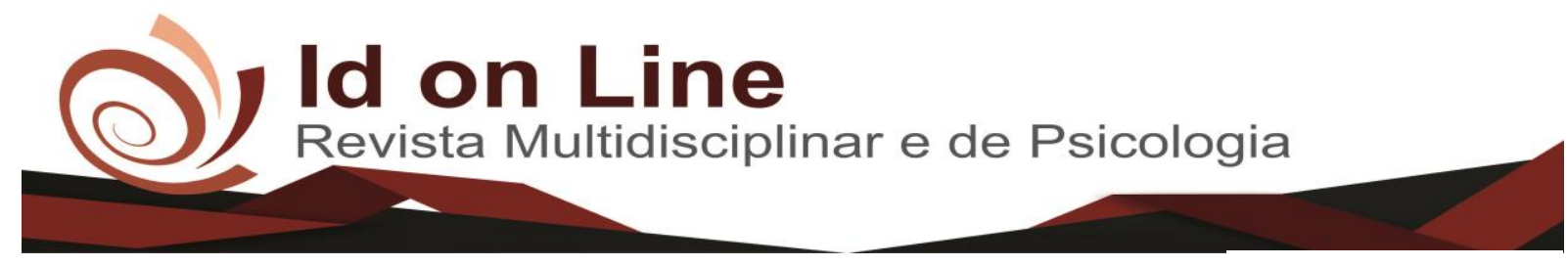

Artigo

\title{
O suicídio de Emma Bovary: Considerações sobre o morrer na obra de Gustave Flaubert
}

\author{
Pedro Walisson Gomes Feitosa ${ }^{1}$; Fábio Gomes de Oliveira ${ }^{2}$
}

\begin{abstract}
Resumo. Este artigo parte da análise literária e psicossocial sobre o suicídio, utilizando como objeto de estudo a personagem Emma Bovary, da obra-prima de Gustave Flaubert, publicado em 1856, na França. Designado como precursor da escola literária do realismo, Flaubert desenhou uma personagem com uma série de nuances que representam dignamente os costumes burgueses europeus da segunda metade do século XIX, bem como transparecem o lugar reservado à mulher neste contexto cultural. O realismo apresentado em Madame Bovary tornou o romance bastante discutido no decorrer dos séculos. Quando publicado em pleno século XIX, a obra erou impactos por toda sociedade, sendo proibida sua publicação na época. Entretanto, a história desenhada minuciosamente por Flaubert sustenta-se atual, pois refere-se tanto ao matar a si como refúgio de uma vida massacrante, como ao enigma da feminilidade ao longo da história, ambas percepções atemporais.
\end{abstract}

Palavras-chave: Suicídio, Morte, Morrer

\section{Emma Bovary's Suicide: Considerations about Dying in Gustave Flaubert's Work}

\begin{abstract}
This article is based on the literary and psychosocial analysis of suicide, using the Emma Bovary character of Gustave Flaubert 's masterpiece, published in 1856 in France. Designated as a forerunner of the literary school of realism, Flaubert drew a character with a series of nuances that dignified European bourgeois customs of the second half of the nineteenth century, as well as the place reserved for women in this cultural context. The realism presented in Madame Bovary made the novel very much discussed over the centuries. When published in the 19th century, the work was impacted by all society, and its publication was prohibited at the time. However, the story drawn by Flaubert in detail, is based on both killing himself as a refuge from a massacring life, and the enigma of femininity throughout history, both timeless perceptions.
\end{abstract}

Keywords: Suicide, Death, Dying

\section{Introdução}

Uma acentuada característica do Realismo Francês era expor a condição humana influenciada por seu meio e a convivência com seus semelhantes. Este movimento literário se utiliza de descrições psicológicas das personagens para obter uma comprovação das suas teori-

\footnotetext{
${ }^{1}$ Universidade Federal do Cariri. Contato: gomesfeitosa.walisson@ outlook.com;

${ }^{2}$ Universidade Regional do Cariri ${ }^{2}$
} 
as, somadas às descrições minuciosas das cenas recorrentes no cotidiano moderno e seus princípios ideológicos.

Desta forma, o leitor, ao invés de esquecer de sua realidade, prendendo-se ao âmbito da ficção, inicia uma procura por seu universo nas tramas realistas. Como relatado por Gasset, 2005:

Um drama agrada à pessoa quando esta conseguiu interessar-se pelos destinos
humanos que lhe são propostos. Os amores, ódios, dores, alegrias das personagens
comovem o seu coração: participa deles, como se fossem casos reais da vida. E diz
que é 'boa' a obra quando esta consegue produzir a quantidade de ilusão necessária
para que as personagens imaginativas valham como pessoas vivas. (GASSET, 2005,
p. 25-26).

Como pode uma obra publicada há mais de um século ser tão contemporânea? Como seria possível a descrição de uma personagem feminina, em pleno século XIX, que ainda passeia pelas ruas, faz compras no mercado ou preside países nos anos 2000? As respostas residem na literatura enquanto fenômeno atemporal e, dessa forma, esta obra é necessariamente revista por diversos olhares, merecendo sempre novas considerações.

Contudo, como levar à percepção científica o que apenas olhares artísticos seriam habitualmente capazes de captar? Este é o caso deste artigo, no qual a Literatura e as Ciências da Saúde unem-se para ler uma magnífica obra: Madame Bovary. O que estaria por trás das histórias que descrevem minuciosamente um suicídio por envenenamento com arsênico? O que nos poderia revelar uma obra que, desde suas primeiras páginas, lida com a morte, o morrer, e a percepção dos que ficam sobre a morte dos seus semelhantes? Por nossa perspectiva, esta obra poderia ser de um profissional especialista em saúde. Profissionais que recebem seu salário para tirar a dor e, como esperado por tantos doentes, a morte dos seus caminhos. O dilema para estes profissionais inicia quando, apesar de todos os esforços humanos e científicos, a morte persevera. O ocorrido leva aos que amaram aqueles que morreram, a necessidade, ou, a obrigação de continuar vivendo sem sua pessoa outrora viva. Aos que cuidaram do que morreu, voltar a trabalhar no outro dia, tendo a morte como uma etapa do viver a ser cumprida por todos, a qual não se pode evitar conviver.

Nesse interim, devemos frisar que delimitamos o nosso estudo ao oitavo capítulo da terceira parte do romance. Buscamos analisar as descrições sobre o suicídio na obra, associando ao entendimento do morrer na obra de Flaubert enquanto precursor do Realismo Francês. Além disso, discutiremos, à luz das ciências biológicas, como fatos da ciência são inseridos na ficção, 
determinando assim, a verossimilhança de uma obra. Este artigo seguiu um método de análise documental, utilizando, além da obra-prima de Flaubert, estudos bibliográficos relacionados ao tema da pesquisa. Consideramos pertinente também um breve histórico sobre o suicídio e sua representação psicossocial.

Madame Bovary, um primor da autoria de um romancista consagrado, o francês Gustave Flaubert, apresenta em sua terceira parte, no capítulo oitavo, os momentos finais de Emma Bovary, desenhando todos os precursores do seu envenenamento por Arsênio. A narrativa de Flaubert apresenta-se tão fidedigna à luz das ciências que parece ter sido escrita por um profissional em Ciências Biológicas. Aqui, discutem-se, além dos princípios psicossociais dos personagens quanto ao morrer, possíveis explicações científicas para alguns dos sinais e sintomas relatados na obra.

\section{Madame Bovary, Gustave Flaubert, 1856}

Quando iniciamos a leitura de um romance pensamos imediatamente em personagens, como vivem, quais problemas enfrentam, que destino terão. Segundo Candido (1964, p.15): “É a personagem que com mais nitidez torna patente a ficção, e através dela a camada imaginária se adensa e se cristaliza."

Emma Bovary destaca-se por sua verossimilhança com as características psicológicas humanas. $\mathrm{O}$ romance difere por tratar um tema rotineiro como a vida de uma aldeã do interior da França. Mais especificamente, em Madame Bovary, é possível notar uma intensa preocupação em encontrar as palavras mais adequadas ao que pretendia narrar. Madame Bovary, de Gustave Flaubert, apresenta Emma, uma personagem jovem romântica e sonhadora, fortemente influenciada por suas leituras, às escondidas, do tempo em que viveu no convento.

Assim como era esperado das mulheres da época, a jovem Emma sonhava m se casar e, ao ser apresentada a Charles Bovary, começou a crer que afinal realizaria um desejo desde a sua estada no convento. As visitas do pretendente à fazenda do pai de Emma a fez acreditar que, enfim, encontrara um príncipe para salva-se de sua estadia tediosa.

Emma entrega-se à união com Charles, viabilizando a fuga de um cotidiano massacrante. Todavia, ao não deparar-se com os luxos exorbitantes que rondavam seus sonhos, protagonista decepciona-se. Os devaneios da Senhora Bovary retornam ao ser convidada, junto 
ao marido, para participar de um o baile. A festa de Vaubyessard é o início da grande reviravolta na história da Madame Bovary. Após esse evento, Emma inicia sua busca pela realização amorosa muito além do seu casamento. Envolve-se com Rodolphe, o conhecido galanteador, e, posteriormente, com Léon, que a conduz às dívidas que a influenciam ao suicídio.

Charles só descobre o que levou sua esposa a tomar esta decisão após a morte dela. É importante frisar que, diante da visão da esposa em leito de morte, e, claramente, sofrendo pelos efeitos causados por arsênico, ele demonstra toda a sua incapacidade diante do fato.

O romance passou por grandes transformações no final do século XVIII e em todo o século XIX. Segundo Brait (1985, p. 30):

[...] é durante a segunda metade do século XIX que o gênero alcança seu apogeu, refinando-se enquanto escritura e articulando as experiências humanas mais diversificadas. Aos realistas e naturalistas coube perseguir a exatidão monográfica dos estudos científicos dos temperamentos e dos meios sociais.

Uma representação nítida da evidencia científica verificada na obra são as dolorosas nuances enfrentadas por Emma. Motivos para os pensamentos suicidas que a protagonista fomenta eram descritos anteriormente a Flaubert e persistem hodiernamente, como exposto adiante. Nesse comportamento de Emma, o veneno apresenta-se como a solução para a trama que entrelaça a sua vida. Mas, a linha entre o curar e o morrer é muito tênue.

\section{Algumas considerações sobre o pensamento suicida}

É, certamente, com Agostinho de Hipona no século V, que o suicídio apresenta-se descrito como um ato pecaminosa. Adiante, ainda na Idade Média, passa a ser considerado crime, pois feria os interesses da Coroa. A partir disso, aqueles que se matavam tinham seus bens retirados pela Coroa, penalizando suas famílias, e os cadáveres passavam por punições. Após a Idade Média, sendo a Coroa separada da Igreja, a influência médica representa um "controle social", destarte, seriam os "médicos" a designarem a morte e si como excessivamente negativa, uma vez que seu significado agora seria patológico, diagnosticado como loucura.

Possivelmente o Cristianismo e seus seguidores contribuíram com a percepção social do suicídio. Primeiramente, os cristãos compartilharam, historicamente, o princípio da vida 
terrena como insignificante diante do paraíso celestial eu deveria ser buscado. Adiante, o clero disseminou o ideal de que a desistência do viver seria um refúgio às dores, que o ser humano seria condenado; assim, um ato punível, uma vez que o sofrer seria sua única obrigação diante de um Deus que julga e condena. Essa análise de que tais indivíduos eram dignos de um castigo especial é exemplificada no clássico Inferno Dantesco, em que os suicidas aparecem vivendo como árvores constantemente arranhadas por hárpias (SILVA, 2009; COSTA, 2011).

A seguinte, com o Renascimento e seu esforço em lutar contra os valores medievais, sustentados pelo individualismo, o dispuser da vida passa a ser considerada uma prática dignamente humana, a ser respeitada pelas sociedades. Tais ideias passaram por constantes repressões da Igreja Católica e dos protestantes.

Consoante Freud, o dilema desenha-se pelo resultado da tensão do sujeito transformado em objeto por uma restrição social dos desejos internos que o aflora, acompanhando sua tendência suicida latente. Portando, uma inclinação suicida poderia emergir quando o indivíduo, submerso pela cultura, somada à adequação social, se entregaria à necessidade de punição sugerida pelo sentimento maquinal de culpa (JUSTUS, 2003).

Nesse viés, vale frisar que essa temática permanece recorrente nas páginas da Literatura e em textos de estudiosos da psique humana. Segundo dados epidemiológicos recentes, estudiosos sugerem que mais de um milhão de pessoas comentam suicídio por ano, em todo o mundo. No Brasil, mesmo com o crescimento do índice em 29,5\% em vinte e seis anos, podemos designa-lo como baixo se comparado às outras nacionalidades. $\mathrm{O}$ índice brasileiro matiza onsoante a região geográfica entre 2,7 a 9,3 casos por cem mil habitantes (LOVISI et al, 2009; PORTELLA et al, 2013).

\section{Sobre o suicídio de Emma Bovary}

Partindo do suicídio como foco dessas reflexões, faremos uma análise dos trechos que constatamos a presença dessa relação: as percepções sobre o ato e os recursos científicos utilizados pelo autor, verificando a maior proximidade com o real, alcançando os objetivos do autor.

“- Justin! - chamou o boticário, que já se impacientava. -Vamos subir! Ele seguiu-a.

A chave girou na fechadura e Ema foi direto à terceira prateleira, tal justeza com que 
a memória a guiava, pegou no frascoazul, destapou-o, meteu-lhe dentro a mão, tirou um punhado de pó branco e pôs-se imediatamente a comê-lo diretamente. - Pare! exclamou o rapaz, agarrando-se a ela. - Cala-te! Pode vir alguém... Justin desesperavase, queria gritar. - Não contes nada, senão recairia tudo sobre o teu patrão! Depois voltou, subitamente calma, e quase com a serenidade de ter cumprido um dever." (FLAUBERT, 2002, p. 372-373. Itálicos nossos).

A partir desse momento, observamos uma série de recursos utilizados por Emma para elaborar sua morte, cada qual com sua específica significância aos objetivos do autor. Como dito por Flaubert em cartas trocadas entre ele e amigos durante o processo de escrita da obra, cada palavra foi minuciosamente calculando, reportando o mais íntimo desejo do autor quanto à sua obra. A chave que abre as portas do armário (quiçá, seria a abertura das portas para sua liberdade?). Além disso, podemos pontuar o medo de ser descoberto fazendo algo prontamente reprovado pela sociedade, pelo empregado, como o receio de Emma, que ingere o veneno com avidez, buscando rapidamente esconder o feito. Essa ocorrência exemplifica as percepções sociais, frutos de um percurso histórico, quanto ao ato do suicídio: vergonhoso e depreciativo.

Outrossim, podemos agora evidenciar as explicações, à luz da ciência, quanto a fenômenos descritos na obra flaubertiano. No trecho recortado acima, já são identificados indícios preciosos quanto a construção científica do envenenamento de Emma Bovary: o frasco azul. Utensílio utilizado ainda hoje na conservação de substâncias químicas, uma vez que o frasco não transparente restringe a incidência de luz no meio interno, reduzindo o risco de perca do efeito de substâncias fotossensíveis, como o arsênio. Flaubert poderia ter descrito como um frasco qualquer, mas, em seu romance, apenas essa descrição não seria suficiente para exemplificar a força da narrativa, logo, detalha-se: frasco azul.

Outro detalhe que nos chama atenção nas descrições do autor é o pó branco; uma cor que representa, desde épocas anteriores à obra, a paz, seria certamente, a que traria "a paz" à Emma, pois esta é a cor que ainda hoje é a principal forma de apresentação dos produtos à base de arsênio.

Seguindo os estudos buscando a integração da obra com diversas áreas do conhecimento, evidenciamos em:

\footnotetext{
“Analisava-se com curiosidade, para descobrir se tinha algum andor. Mas não! Ainda nada. Ouvia o tique-taque do relógio, o crepitar do lume e a respiração de Charles, de pé, ali junto da cama. "Oh! A morte é uma coisa insignificante!", pensava ela, "vou adormecer e estará tudo acabado!" Bebeu um gole de água e voltou-se para a parede. Aquele horrível gosto a tinta persistia. “...Estou com sede! Estou com muita sede! suspirou ela [...] E foi acometida de tão súbita náusea, que mal teve tempo de lançar mão do lenço que tinha debaixo do travesseiro. - Leva-o! - disse precipitadamente. -
} 
Deita-o fora! [...] [...] Às oito horas reapareceram os vômitos Charles observou que havia no fundo da bacia uma espécie de areia branca, agarrada à porcelana. - É extraordinário! É singular! - repetia ele." (FLAUBERT, 2002, p. 374-375).

A evidência de vômitos e sede são devidamente compreendidos pela Medicina, afinal, são notados pela ciência, principalmente, duas formas de ação do arsênio, um agente altamente tóxico. A primeira é que ele apresenta um alto potencial para causar hepatotoxicidade por infiltração gordurosa e cirrose. A outra seria que, ao bloquear sistemas enzimáticos essenciais, ele altera o metabolismo celular, causando lesão capilar difusa e vômitos com sangue. Essas ações podem explicar as fortes dores relatadas por Emma.

Prossegue-se o recorte dos momentos finais de Emma Bovary:

\begin{abstract}
"Então ele, delicadamente e quase a acariciando, passou-lhe a mão sobre o estômago. Emma soltou um grito agudo. Charles recuou aterrado. Depois ela pôs-se a gemer, a princípio muito levemente. Um grande arrepio sacudiu-lhe os ombros e começou a ficar mais pálida que o lençol onde se lhe afundavam os dedos crispados. O pulso irregular era agora quase imperceptível. Surgiram-lhe gotas de suor espalhadas pelo rosto azulado que, entorpecido, parecia exalar um vapor metálico. Batia os dentes, com os olhos dilatados olhava vagamente em torno, e só respondia a todas as perguntas abanando a cabeça, chegou a sorrir duas ou três vezes. Pouco a pouco, os gemidos foram-se tornando mais fortes. Deixou escapar um uivo surdo, disse que estava melhor e que dali a pouco se levantaria. Mas entrou em convulsões e exclamou: - Ah! É atroz, meu Deus!” (FLAUBERT, 2002, p. 375).
\end{abstract}

A obra de Flaubert possibilita a leitura da morte, quiçá, a mais bem desenhada da história da literatura. Todavia, precisamos pontuar que Emma Bovary nada mais apresentava que os típicos efeitos tóxicos do arsênico: anemia, hipotensão e arritmia cardíaca. Sob a ótica da Medicina, sabemos que alterações hematológicas e cardiovasculares são os consequentes efeitos evidenciados logo após uma agressão gastrintestinal gerada pelo arsênio. Depois das alterações nesses sistemas orgânicos, são descritos efeitos neurológicos do arsênico:

\begin{abstract}
"Subitamente ouviu-se no passeio um ruído de grossos tamancos, juntamente com o arrastar de um cajado, e uma voz rouca que começou a cantar: Quantas vezes um belo dia de calor Faz sonhar as meninas com amor. soltos, o olhar fixo, a boca aberta. Para apanhar as espigas que os moços foram ceifar, na noite com as moças andou no campo a cantar. - O cego! - gritou Ema. E começou a rir, um riso cruel, delirante, desesperado, julgando ver o rosto medonho do desgraçado surgir nas trevas eternas como um fantasma... Em seguida veio uma convulsão, que a fez se deitar novamente. Todos se aproximaram. Ema não existia mais" (FLAUBERT, 2002, p. 386).
\end{abstract}

Dentre os principais danos ao Sistema Nervoso Central, são relatados como típicos desse tipo de intoxicação as alucinações, os delírios e as convulsões. Podem ocorrer ou não as 
alterações na consciência. A agressão aos neurônios pode causar vários distúrbios do movimento, como as convulsões. Seguindo a categorização de Durkenheim, poderíamos nos perguntar qual o tipo de suicídio cometido pela protagonista. Muitos poderiam indica-la como "egoísta", por ela buscar livrar-se da angústia relacionada às dívidas financeiras e à dor de ter sido abandonada por seu último amante. Mas alguém não poderia indicar alguma abnegação no seu ato? Talvez Emma, se sentindo digna de uma pena de morte, não teria buscado poupar o marido de sujar as mãos de sangue ou, talvez, de conviver com a vergonha de não fazê-lo? Dessa forma, o caso Madame Bovary pode ser analisado em qualquer forma de exposição sobre o comportamento suicida, como exemplo da percepção psicológica de que esse ato escoa de como o indivíduo reage ao frenesi entre as suas ideações e o comando social que as contém.

Além das coerentes descrições quanto ao processo patológico do envenenamento, a obra de Flaubert oportuna uma reflexão quanto ao suicídio como comportamento humano recorrente, não superado hodiernamente. Destarte, confirmamos que esta é uma forma necessária de demostrar a quem lê literatura que esta arte é atual e pode ser fonte dos inúmeros e mais diversos questionamentos.

Logo, refletimos que o suicídio como caminho para a resolução das adversidades cotidianas, destaca-se enquanto obra-prima da literatura universal como precursor da visão que revelaram-se por escritores e filósofos dos meados do século XX, ao desenharem a noção do Existencialismo. Por que recomeçar se os problemas são impossíveis de resolução? Teria sido este o último pensamento de Emma Bovary? Dessa forma, a morte por envenenamento seria, na verdade, um antídoto.

\section{Referências}

FLAUBERT, Gustave. Madame Bovary. Trad. Enrico Corvisieri. São Paulo: Nova Cultural Ltda, 2003.

GASSET, José Ortega y. A desumanização da arte. Trad. Ricardo Araújo. São Paulo: Cortez, 2005.

BRAIT, Beth. A Personagem. São Paulo: Ática S.A, 1985.

CANDIDO, Antonio. A Personagem de Ficção. $2^{\circ}$ Ed. São Paulo: Perspectiva, 1964. 
SILVA, L. M. A.; COUTO, L. F. A questão do suicídio: algumas possibilidades de discussão em Durkheim e na Psicanálise. Arq. bras. psicol., Rio de Janeiro, v. 61, n. 3, dez. 2009. Disp.em<http://pepsic.bvsalud.org/scielo.php?script=sci_arttext\&pid=S1809-

$52672009000300007 \& \operatorname{lng}=$ pt\&nrm=iso $>$.

SILVA, M.C.M. Renúncia à vida pela morte voluntária: o suicídio aos olhos da imprensa no Recife dos anos 1950. 2009. 143 p. Dissertação (Mestrado em História). Universidade Federal de Pernambuco, Recife.

COSTA, D. L. O estigma e sua representação no inferno dantesco. Seminário de Pesquisa do Programa de Pós-graduação em História Social da Universidade Estadual de Londrina, 5, 2011, Londrina. Anais... Vol3, p. 31-43. Disponível em: <http://www.uel.br/pos/mesthis/Anais_Vol3.pdf\#page=31>.

JUSTUS, D. O suicídio nosso de cada dia... In: Estados Gerais da Psicanálise: Encontro Mundial, 2, 2003, Rio de Janeiro. Anais... Disponível em: <http://www.egp.dreamhosters.com/encontros/mundial_rj/download/5c_Justus_41040903_po rt.pdf $>$.

LOVISI, G. M. et al. Análise epidemiológica do suicídio no Brasil entre 1980 e 2006. Rev. Bras. Psiquiatr. São Paulo, v. 31, supl. 2, Oct. 2009. Disponível em: $<$ http://www.scielo.br/scielo.php?script=sci_arttext\&pid=S 151644462009000600007\&lng=en $\& n r m=$ iso $>$.

PORTELLA, C. H. et al .Epidemiological profile of suicide in the Santa Catarina Coal Mining Regionfrom 1980 to 2007.TrendsPsychiatryPsychother., P Alegre, v. 35, n. 2, 2013. Disp. $\quad$ em<http://www.scielo.br/scielo.php?script=sci_arttext\&pid=S2237$60892013000200006 \& \operatorname{lng}=\mathrm{en} \& n \mathrm{~nm}=\mathrm{iso}>$.

Como citar este artigo (Formato ABNT):

FEITOSA, Pedro Walisson Gomes; OLIVEIRA, Fábio Gomes de. O suicídio de Emma Bovary: Considerações sobre o morrer na obra de Gustave Flaubert. Id on Line Rev.Mult. Psic., 2018, vol.12, n.42, p.13-21. ISSN: 1981-1179.

Recebido: 08/08/2018.

Aceito: 09/08/2018 